\title{
Mechanisms associated with September to November (SON) rainfall over Uganda during the recent decades
}

\author{
Hamida Ngoma ${ }^{A}, C^{*}$, Wang Wen ${ }^{A}$, Brian Ayugi ${ }^{A}, B, E$, Rizwan Karim ${ }^{A}$, Exavery Kisesa Makula ${ }^{A, D}$ \\ Received: December 19, 2020 | Revised: February 14, 2021 | Accepted: February 25, 2021 \\ doi: 10.5937/gp25-29932
}

\begin{abstract}
This study revisits teleconnections associated with the anomalous events of September to November (SON) rainfall over Uganda during 1981-2019, owing to the recent intensification of extreme events. Empirical Orthogonal Function (EOF), Composite and Correlation analysis are employed to examine the variability of SON rainfall over the study domain and associated circulations anomalies. Thefirst EOF mode (dominant mode) displays a positive monopole pattern and explains $67.2 \%$ of the variance. The results revealed that SON rainfall is largely influenced by a Walker circulation mode over the Indian Ocean, whereby, wet events are associated with an ascending limb of the Walker circulation on the western part of the Indian Ocean characterized by convergence at low levels and divergence at upper level. The study showed that SON rainfall is positively (negatively) correlated with Indian ocean (Atlantic Ocean) sea surface temperatures (SST). Furthermore, Indian Ocean Dipole (IOD) events have impact on SON rainfall with strong positive correlation, whereas Southern Oscillation Index (SOI) revealed negative correlation. The results also reveal that there is a lag in ENSO and IOD episodes during wet/dry events over the region. ENSO and IOD also tend to extend the rainfall season of SON and thus study of extreme events may not be well captured by studies focusing on SON. Future studies might consider the season of October to December or December to February. These phenomena need to be closely monitored and considered when making seasonal forecasts.
\end{abstract}

Keywords: Rainfall; Extreme; Circulation; Uganda; East Africa

\footnotetext{
A Key Laboratory of Meteorological Disaster, Ministry of Education (KLME)/Joint International Research Laboratory of Climate and Environment Change (ILCEC)/Collaborative Innovation Center on Forecast and Evaluation of Meteorological Disasters (CICFEMD), Nanjing University of Information Science and Technology, Nanjing 210044, China; hamynads@gmail.com; wangwen@nuist.edu.cn; rizwan555danyore@gmail.com

B Jiangsu Key Laboratory of Atmospheric Environment Monitoring and Pollution Control, Co llaborative Innovation Center of Atmospheric Environment and Equipment Technology, Scho ol of Environmental Science and Engineering, Nanjing University of Information Science and Technology, Nanjing 210044, China; ayugi.o@gmail.com

c Department of Geography, Geoinformatics and Climatic Sciences, Makerere University, P.O. Box 7062, Kampala, Uganda; hamynads@gmail.com

D University of Dar es Salaam, Physics Department, P.O. Box 35063, Dar es Salaam, Tanzania; kisesaexavery@yahoo.com

E Organization of African Academic Doctors (OAAD), Off Kamiti Road P.O. Box 25305-00100, Nairobi, Kenya

*Corresponding author: Hamida Ngoma; e-mail: hamynads@gmail.com
} 
Uganda is an agricultural country and the economy largely depends on rainfed agriculture. Abnormal occurrences in rainfall have far-reaching effects on community livelihoods (GOU, 2015). Rainfall over the region exhibits high spatial and temporal variability. This is attributed to the complex topography, varying vegetation patterns and large inland water bodies which regulate the local climate (Basalirwa, 1995; Ogwang et al., 2014). Rainfall over the region is mostly influenced by the equatorial rain band which oscillates northwards and southwards throughout the year (Nicholson, 1996; 2018). This convergence zone over the region is twice a year, thus resulting into bimodal rainfall patterns over the study domain. The long rains occur between March to May (MAM) and short rains between September to November (SON) (Basalirwa, 1995). However, this tends to a unimodal pattern for areas away from the equator. Other factors influencing rainfall over the region include westerlies from Congo basin, monsoons, anticyclones; the Mascarene High, Arabian High, Azores High and the St Helena High, sea surface temperature (SST) anomalies, El-Nino Southern Oscillation (ENSO) and Indian Ocean Dipole (Saji et al., 1999; Indeje et al., 2000; Ogwang et al., 2012; 2015).

Extreme weather events in form of droughts and floods have been reported over the region by previous studies (Ogwang et al., 2015; Nicholson, 2017; Ojara et al., 2020). These are as a result of below normal, above normal or changes in onset, frequency, duration, and intensity of rains in different seasons. This has posed pronounced consequences on the population. Past studies have reported an observed decrease in rainfall during MAM season and an increase during SON (Nsubuga et al., 2014; 2017; Egeru et al., 2019; Ngoma et al., 2021). Nevertheless, SON rains have exhibited higher interannual variability as they are reported to be more influenced by global teleconnections (Saji et al., 1999; Ongoma et al., 2015). Therefore, a clear understanding of the various mechanisms regulating the short rains of SON is paramount so as to improve on seasonal climate forecasts for disaster mitigation and adaptation.

Over the Greater Horn of Africa, various studies have been conducted to investigate the mechanisms influencing climate over the region (Indeje at al., 2000; Hastenrath et al., 2004; Williams \& Funk, 2011; Manatsa et al., 2012; 2014; 2015; Ongoma et al., 2015; Nicholson, 2017; 2018; Ayugi et al., 2018). A majority of these studies also focused on the short rains due to its higher interannual variability (Hastenrath et al., 2004; 2011; Manatsa et al., 2014; Ogwang et al., 2014). Hasternrath et al. (2011) reported that the short rains are mostly influenced by a zonal vertical circulation cell in the central equatorial Indian Ocean known as the Walker circulation. Numerous studies demonstrate that the most important physical mechanism in the variability of the short rains is the intensity of this cell, with the low-level westerlies playing a fundamental role inmodulating this cell (Mutai et al., 2012; Limbu \&Tan, 2019). It is noted that strong westerlies are favoured by a steep eastward pressure gradient and abnormally weak trade winds in theSouth Indian Ocean (Nicholson, 2017). The weakening of the equatorial westerliesacts to reduce the subsidence over East Africa.Warm SSTs in the west and cold SSTs in the east are associated with a weakenedWalker circulation over the Indian Ocean.

On the other hand, some studies link anomalous wet events of the short rains to effects by the Pacific Ocean (ENSO) (Nicholson \& Kim, 1997; Indeje et al., 2000). It is reported that short rains are enhanced during El-Nino years and reduced during La-Nina years. According to Nicholson (2015), ENSO is well correlated with parameters over the Indian Ocean that modulate the short rains, such asthe low-level and upperlevel zonal winds. It is noted that a higher phase of Southern Oscillation (SO) weakens south easterlies from the Indian Ocean and lowers pressure over the eastern Indian Ocean. It is documented that ENSOplays a significant role in determining the monthly and seasonal rainfall patterns in the East Africanregion (Black et al., 2003; Nicholson \& Kim, 1997).Most of these studies were carried out over the entire East Africa or Greater Horn of Africa and a few focusedon Uganda. Thus, they do not capture well the localized patterns and the local circulations involved over Uganda.

The recent decades have witnessed an intensification of anomalous events over the study region compared to the last 50 years of observed climatology. For instance, the 2019 short rains over Uganda were considered the most pluvial year observed, affecting thousands of people and destroying the societal infrastructure (ReliefWeb, 2020). The need for accurate forecasting as a way of minimizing the losses remains a paramount process. Towards the detected signature event in 2019, the Climate Outlook Forum (COF53) attributed the events to several factors. They were as follows: the forecasted warmer positive phase of IOD, the Neutral ENSO conditions in the central and east pacific Oceans, and dynamical factors, among others (UNMA, 2019). The extensive probabilistic features for predictions of the exact cause could be attributed to the deficiency in understanding the teleconnec- 
tion's patterns influencing the seasonal rainfall. Recent studies have pointed to these new phenomena that affect the rainfall variation over the larger East African region but no studies conducted over Uganda, despite the large spatial variance (Finney et al., 2019; Wainwright et al., 2020). For instance, the effect of Madden-Julian Oscillation (MJO) and the presence of tropical cyclones in the Western Indian Ocean (WIO) has been detected to contribute to the recent climate extremes. Another recent study by Ogwang et al. (2014) assessed circulation anomalies of October to December extreme rainfall and covered whole East Africa. Furthermore, Ogwang et al. (2016) pointed out that there was an abrupt change in SON rainfall over Uganda during 1994. Thus, with the expected changes in climate, there is call for the need to revisit the possible mechanisms influencing the SON short rains over Uganda for accurate weather and climate prediction.

This study therefore sought to investigate the mechanisms influencing short rains over Uganda in the recent decades (i.e.,1981 - 2019) and fill in the gap by past studies. Section 2 gives a brief description of the study domain, the data and methods employed in the study. Section 3 presents the findings and discussions of the study. Lastly section 4 gives the summaryand presents possible recommendations.

\section{Study Area, Data and Methods}

\section{Study Area}

Uganda is located in East Africa and stretches from $29.2^{\circ} \mathrm{E}-35.2^{\circ} \mathrm{E}$ and from $1.5^{\circ} \mathrm{S}-4.5^{\circ} \mathrm{N}$ (Fig. 1). It is a landlocked country bordered by South Sudan in the North, Kenya in the East, Democratic Republic of Congo (DRC) to the West and Rwanda and Tanzania in the South. The country comprises of complex topography ranging from low lying areas in the north west, middle terrain in the central to high lands and top mountains in the south west (Mts Rwenzori and Mufumbira), and north east (Mts Elgon and Moroto). Various water bodies also cover up some parts of the country including Lakes Victoria, Kyoga, Albert, Edward and George and rivers including the world's longest river, River Nile. The climate of region is equatorial with tropical forests rain forest such as Mabira Forest. All these physical features regulate climate over the region through local induced convection. As mentioned earlier in the introduction section, the climate over the region is mostly influenced by the tropical rain belt which

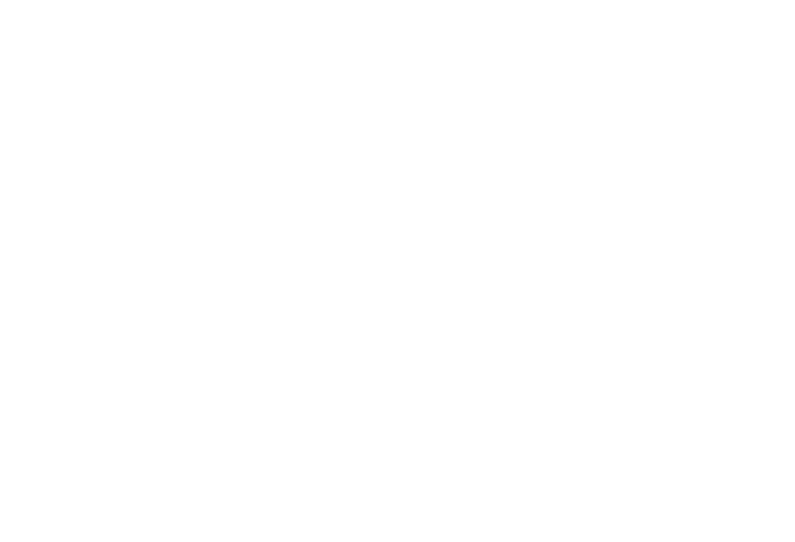

Figure 1. Location of Uganda in Africa along longitudes $29.2^{\circ} \mathrm{E}$ and $35.2^{\circ} \mathrm{E}$, and latitudes $1.5^{\circ} \mathrm{S}-4.5^{\circ} \mathrm{N}$. Also indicated include the presence of physical features, water bodies and elevation in meters $(\mathrm{m})$. oscillates from north to souththroughout the year (Basalirwa, 1995; Nicholson, 2018).

\section{Data}

\section{Observed datasets}

Station data over Uganda has many discrepancies (Sylla et al., 2012). This is due to the sparse distribution of ground stations and unreliability of equipment. This study therefore used monthly rainfall estimates from the Climate Hazards Centre for Infrared Precipitation with Station data(CHIRPS) (Funk et al. 2015) as a reference to observed data from 1981 to2019 relative to the starting period of the datasets. The data is available on http://https://www.chc.ucsb.edu/data/ chirps.The CHIRPS rainfall data version 2 (CHIRPS. v2) blends $0.05^{\circ}$ resolution satellite imagery with in-situ measurements toproduce a gridded value from 1981 to present. CHIRPS has been evaluated and utilized by a number of studies over East Africa (Dinku et al., 2018; Ayugi et al., 2019; Ngoma et al., 2021).

\section{Reanalysis Datasets}

The study employed ERA5 reanalysis dataset $(\mathrm{C} 3 \mathrm{~S}, 2017)$ at $0.25^{\circ} \times 0.25^{\circ}$ horizontal resolution for winds (zonal $\mathrm{u}$ and meridional $\mathrm{v}$ ), vertical velocity and specific humidity at $850 \mathrm{hPa}$ and $200 \mathrm{hPa}$ for comparison with large-scale circulation.ERA5 isthe 5th generation product available from the European Centre for Medium-Range Weather Forecasts (ECM$\mathrm{WF})$.Winds at $850 \mathrm{hPa}(200 \mathrm{hPa})$ was selected because these are linked to low-level (high-level) wind convergence (divergence) that has direct influence on rainfall trends over the study region.

Variables of mean sea level pressure and velocity potential were obtainedfrom the National Centers for Environmental Prediction-National Center for Atmospheric Research (NCEP-NCAR) from https://psl. 
noaa.gov/data/gridded/data.ncep.reanalysis.htmlat at $2.5^{\circ}$ resolution. Version 5 sea surface temperature was obtained from National Oceanic and Atmospheric Administration/National Climatic Data Center, NOAA NCDC at http://iridl.ldeo.columbia.edu/SOURCES/. NOAA/.NCDC/.ERSST/.version5/.sst for the same study period 1981-2019. The study further utilized Southern Oscillation Index (SOI) and Dipole Mode Index (DMI) datasets to investigate the influence of ENSO and Indian Ocean Zonal Mode on SON rainfall over Uganda. These indices were obtained from NOAA at https://psl. noaa.gov/gcos wgsp/Timeseries/.

\section{Methods}

The study employed various methods like Empirical Orthogonal Function (EOF), composite analysis, student t-test and simple correlation.EOF is used to investigate the variability of a single field of climatic data (Lorenz, 1956).The variability in the time evolving field is broken down into a few standing oscillations and a time series (Principal Component) for each oscillation. The first EOF is the leading mode and points to thedirection in which the data vectors jointly display the most variability. The secondeigenvector is perpendicular to the first eigenvector, which is perpendicular to the thirdeigenvector and so on, thus called the empirical orthogonal function analysis. Well correlated data may be defined by a small number of orthogonal functions andtime coefficients, corresponding to the variances in theirspatial and temporal distribution (Bjornsson \&Venegas, 1997). EOF is used in this study to show the dominant modes ofvariability of SON rainfall over the region. This technique has been employed by a numberly of studies across East Africa (Ogwang et al.,2012; Ayugi et al., 2018;Limbu \&Tan,2019).The data used is normalized in order to prevent areas andseasons of maximum variance from dominating the eigenvectors. Thestandardized rainfall anomaly (z) is computed as shown in equation 1 .

$$
\text { Anomaly }=\frac{X-\bar{X}}{\sigma}
$$

- where $X$ is the SON mean rainfall, $X$ is the longterm SON mean rainfall and $\sigma$ is standard deviation of SON rainfall.
The composite analysis involves identifying and averaging different fields of a variable selected according to their association with key conditions.Composites were separately analyzed for Mean sea level pressure, winds, moisture flux convergence, vertical velocity, and velocity potential. This method was used to detect circulation patterns associated with anomalous events of wet and dry years. Wet (dry) years are defined by values of $>1(<1)$ standard deviation from the time series of the principal component (PC) of the dominant mode of EOF as explained in studies by Dommenget and Latif (2002) and Makkonen (2006). The results of the composites are used to generate hypotheses for patterns associated with individual scenarios variability.

The composite variables were tested for statistical significance using the t-test (when one or both groups have a sample size of less than 40). The equations for $\mathrm{t}$ test are as shown in equation 2 and 3 .

$$
\begin{aligned}
& t=\frac{\bar{x}_{1}-\bar{x}_{2}}{S_{\bar{x}_{1}-\bar{x}_{2}}} \\
& S_{\bar{x}_{1}-\bar{x}_{2}}=\sqrt{\frac{\left(n_{1}-1\right)}{n_{1}+n_{2}-2}} S_{1}^{2}+\left(n_{2}-1\right) S_{2}^{2}\left[\frac{1}{n_{1}}+\frac{1}{n_{2}}\right]
\end{aligned}
$$

- where $\bar{x}=$ mean

- $\mathrm{S}=$ standard deviation.

The calculated values of $t$ were compared with those of the theoretical distribution with N-2 degrees of freedom at different significance levels. If the calculated value of tis less than the theoretical value, then the significant area identified. Lastly, correlation analysis for Pearson correlation coefficient was employed to study the relationship between SON rainfall and SST, SOI and DMI. The simple correlation has two important properties. First, it is bounded by -1 and 1, i.e., $-1<\mathrm{CC}<1$. When the value of correlation coefficient +1 or -1 , it indicates a perfect positive or negative correlation between thegiven pairs of variables, respectively. The square of the correlation coefficient represents theportion of the variability of one of the two variables that is linearly accounted for or explained by theother.

\section{Results and Discussions}

\section{Spatiotemporal variability}

Figure 2 shows standardized precipitation anomalies for SON rainfall based on CHIRPS data during 1981-2019 over Uganda. High interannual and interdecadal variability is shown over the region with almost equal number of wet and dry events. 19 years exhibited wet patterns whereas 20 years experienced dry precipitation anomalies. Significant anomalous events with standardized anomaly of $>(<) 1$ occurred during 2011,2012, 2019 (2005, 2009).Previous studies have attributed these anomalous events to the dipole mode influence of the Indian Ocean sea surface tem- 
peratures (Saji et al., 1999; Manatsa et al., 2012). Wet (dry) events are associated with positive (negative) Indian Ocean dipole. Other studies link the interannual variation of SON rains to El Niño Southern Oscillation (ENSO) (Indeje et al., 2000; Ntale and Gan 2003). This is also reflected by the present study with El Niño years coinciding with wet anomalous events of 2010 and 2012 and La Niña years with dry events of 2005, 2009. However, some years reported by previous studies as El-Nino and La- Nina are not reflected in the wet and dry years. An example is 1996-1997 which was a strong El-Nino year but depicting slightly above normal rainfall in Figure 2. This could be attributed to the characteristic of the episodes as reported by a study (Hoell et al., 2014) which found that the short rains are generally reduced during La Niña but that the degree and spatial consistency of the reduction depends on the nature of the episode. Nicholson et al. (2001) also found that the impact of La Niña/El Niño materialized only when cooling/warming of thetropical Indian and Atlantic Oceans occurred in conjunction with the episode. These events are also known to prolong the rainfall season of SON sometimes extending it to January. An example is the heavy rains of 2019 that resulted into flooding and landslides in various parts of the country. The rains started late October and persisted till mid-January 2020 in most parts of the country (ReliefWeb, 2020). This usually leads to destruction of property, damaged infrastructure, poor transport conditions, and increase in food prices.

Furthermore, the spatiotemporal variability of rainfall during SON season was assessed using EOF. Figure $3(a, b, c)$ shows the spatial component of the first three eigen vectors and the corresponding principal components (d, e, f). The three modes account for $99.9 \%$ of the entire rainfall variability over the region.

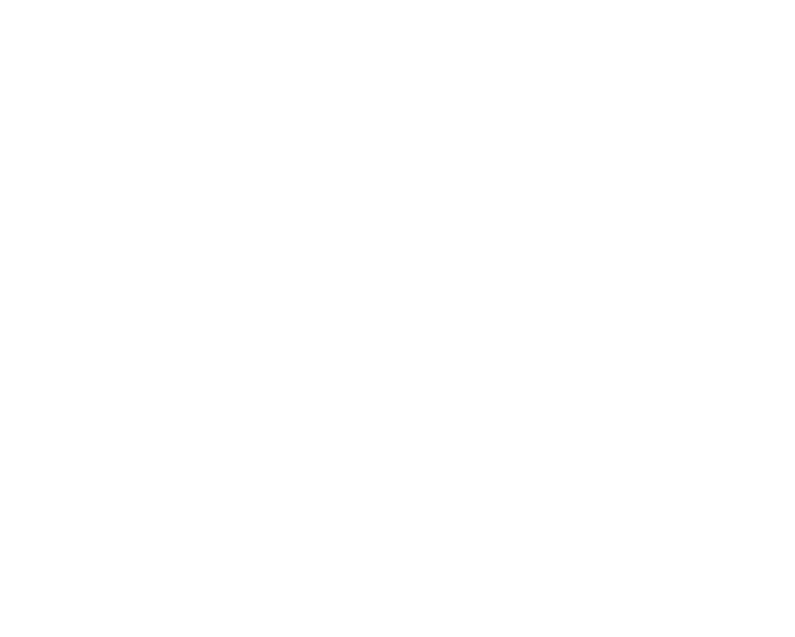

Figure 2. Standardized anomalies of mean SON rainfall (mm/month) over Uganda during 1981-2019 based on CHIRPS datasets averaged along longitudes $29.2^{\circ} \mathrm{E}-35.5^{\circ} \mathrm{E}$ and latitudes $1.5^{\circ} \mathrm{S}-4.5^{\circ} \mathrm{N}$
Independently they explain $67.2 \%, 21.8 \%$ and $10.9 \%$ of the total variance. EOF 1 exhibits a monopole variability pattern of entirely positive loading over the study domain, with more strong loadings over the eastern parts of the country, around Lake Victoria, and Lake Kyoga region. This could be attributed to effect of local meso-scale convection thus the modified rainfall patterns. The southwest and north-easternparts of the country exhibit the weakest loadings. The first EOF 1timeseries (PC1) captures well the observed patterns of interannual variability of rainfall during SON season as demonstrated in Figure 2. Anomalous events with wet patterns(>1) include 2001, 2011, 2015 and 2019. On the other hand, years characterized with dry patterns $(<1)$ include 1993, 2005, 2009 and 2018. EOF 2 and EOF 3 display a dipole pattern. EOF 2 exhibits positive loading towards the eastern part and negative loading to the west. However, EOF 3 shows positive loading to the north and negative loading to the south of the study region. The timeseries of the second and third modes (PC 2 and PC 3) do to not capture well the observed rainfall patterns over Uganda. Thus, this study used PC 1 of the first and dominant mode for identifying wet and dry years with standardized anomaly of $+/-1$ respectively. The identified years are then utilized in composite analysis to investigate the possible circulations associated with the anomalous events. Table 1 shows wet and dry years from PC1.These results agree with previous studies by Ogwang et al. $(2012,2016)$ conducted over Uganda for the period 1962-2007, 1901 - 2013 respectively. However, some differences are exhibited in these studies in the percentage variance explained by the dominant modes of the EOFS. One study that utilized ground station datasets depicted low percentage $(24 \%)$ by the EOF compared to the other that employed gridded datasets from the Climatic Research Unit (CRU). This could be attributed to the uneven distribution of station over the study domain. There is also controversy in the years between revealed as wet and dry years in the recent study and previous studies (Ogwang et al., 2012; Ogwang et al., 2014; Ogwang et al., 2016). The results reveal that some the years reported in previous studies as El-Nino and La-Nina years were not recorded as extremely anomalous years. This could be attributed to the differences in season as some studies focused on October to November rainfall season and also probably inability of gridded datasets to accurately reproduced interannual variability of observed rainfall over the region.

\section{Circulations associated with wet and dry years}

Circulation characteristics are important in depictingthe dynamical factorsassociated with the observed weather eventsfor predicting future weather 

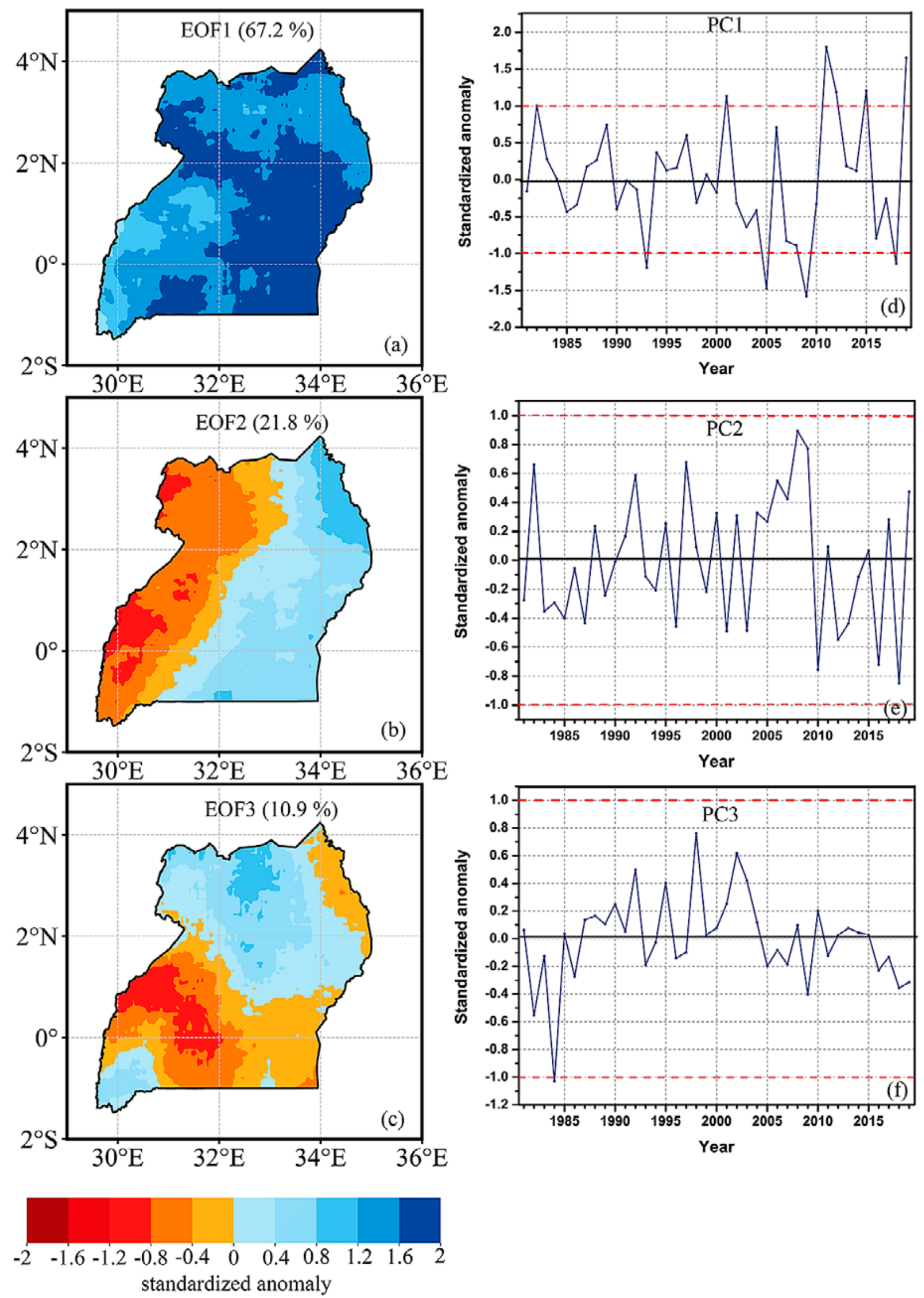

Figure 3. EOF distribution of the first three dominant modes $(a, b, c)$ and Principal components $(d, e, f)$ of SON rainfall over Uganda during 1981-2019 based on CHIRPS data. The first mode represented $67.2 \%$ of the SON rainfall over the region 
Table 1. EOF 1 for wet and dry years based on PC 1 for SON rainfall over Uganda between 1981-2019 wherez represents standardized anomaly.

\begin{tabular}{|l|l|l|l|l|}
\hline Season & Grades & years & Condition: Anomaly (z) & Occurrence (\%) \\
\hline \multirow{3}{*}{ SON } & Above normal rainfall (wet) & $2001,2011,2015,2019$ & $\mathrm{z}>1$ & 10.3 \\
\cline { 2 - 5 } & Below normal rainfall (dry) & $1993,2005,2009,2018$ & $\mathrm{z}<1$ & 10.3 \\
\cline { 2 - 5 } & Normal rainfall & $1981,1982,1983,1984,1985,1986,1987$, & $1<z>1$ & 79.4 \\
& & $1988,1989,1990,1991,1992,1994,1995$, & & \\
& $1996,1997,1998,1999,2000,2002$, & & \\
& $2003,2004,2008,2007,2008,2010$, & & \\
& $2012,2013,2014,2016,2017$ & & \\
\hline
\end{tabular}

patterns. This study analyzed mean sea level pressure, wind, moisture flux, vertical velocity and velocity potential.

\section{Pressure systems, wind and moisture flux}

Figure $(4 a, b, c)$ shows mean sea level pressure anomalies during wet, dry and wet-dry years. During wet years (Fig. 4a, c), the Arabian high-pressure system strengthens and is situated over Sudan. The Mascarene High over the south Indian Ocean on the other hand weakens. This positions the rain band over the study region, and is accompanied by north westerlies and westerlies from Congo and easterlies from the Indian Ocean (Fig. 5a, e). In contrary during dry years (Fig. 4b), the Arabian high weakens and the Mascarene High intensified. The ridging is extended over some parts of East Africa and thus moving the loci of cloud clusters associated with westward propagating tropical wave disturbances above the region. This results to weak westerlies towards the study region. As noted by previous studies including Mutai et al. (2012) and Defzuli and Nicholson., (2013), strong westerlies are favored by a steep eastward pressure gradient and abnormally weak trade winds in theSouth Indian Ocean.
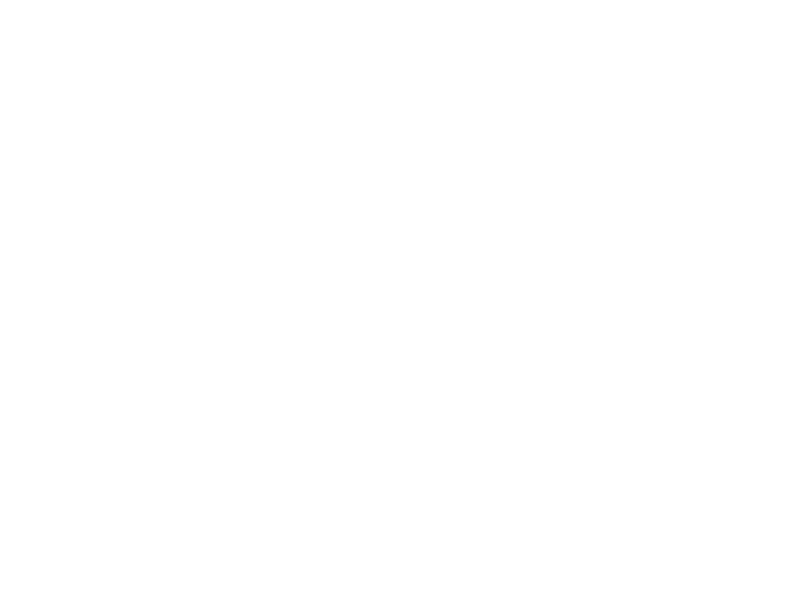

Figure 4. Mean sea level pressure anomalies (hPa) during (a) wet years, (b) dry years and (c), Wet-Dry years based on NCEP reanalysis datasets over Uganda for the period 1981-2019. The shaded area is significant at 0.1 significance level
Figure (5a, b,c,d,e,f) shows wind anomalies during wet, dry, and wet-dry years at $850 \mathrm{hPa}$ and $200 \mathrm{hPa}$. At the lower level $(850 \mathrm{hPa})$, wind is generally weak and strong at higher level $(200 \mathrm{hPa})$. During wet years, moist westerlies from Congo are observed in conjunction with easterlies from the Indian Ocean. This is accompanied by strong easterlies at upper level.The winds blowing from the Congo forest in DRC are generally warm and moist with high speed, and thus they likely contribute to the observed above-normal rainfall during wet years. The flow converges at lower lev-
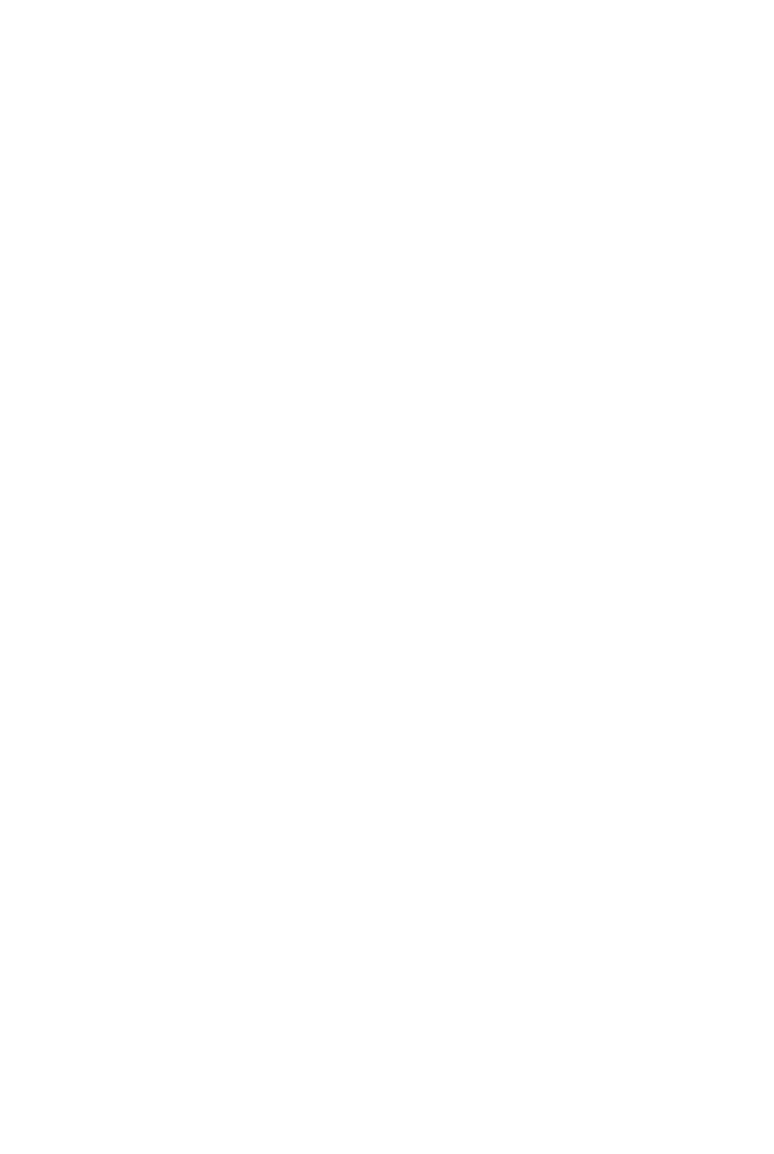

Figure 5. composites of wind anomalies $(\mathrm{m} / \mathrm{s})$ at $850 \mathrm{hPa}$ (a) and 200 (c) for wet years, $850 \mathrm{hPa}$ (b) and $200 \mathrm{hPa}$ (d) for dry years and, $850 \mathrm{hPa}(\mathrm{d})$ and $200 \mathrm{hPa}$ (e) of wet-dry years for SON rainfall season over Uganda based on CHIRPS and ERA5 data for the period 1981-2019. The shaded area is significant at 0.1 significance level 


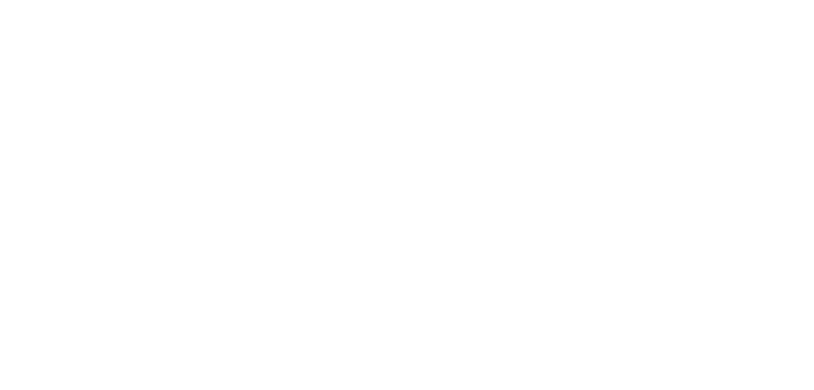

Figure 6. Moisture flux convergence $\left(10^{-5} \mathrm{~g} \mathrm{~kg}^{-1} \mathrm{~s}^{-1}\right)$ at 850 $\mathrm{hPawhere} \mathrm{positive} \mathrm{values} \mathrm{representpositive} \mathrm{moisture} \mathrm{flux}$ convergence during wet years (a) and dry years (b)

els and diverges at higher levels, thus wet years are marked by rising motion to the western part of the Indian Ocean and the study area.In contrary, dry years are characterized by weak westerlies and south easterlies from the Indian ocean without convergence at low level. The southeasterlies originating from the Indian Ocean weakens considerably when passing the Kenya and Tanzania highland before entering in Uganda. At upper level, strong westerlies are observed with convergence over the Indian ocean. This reduces water vapor transportation and lowers convection.

Composites of mean moisture flux for wet and dry years is shown in Figure 6. The results reveal that there is more positive anomaly (moisture convergence) and convergent winds during wet years than dry years (Fig.6a). Having sufficient moisture coupled with low-level convergence over the study area results to ascending motion and enhanced convection which later favours anomalous rainfall (anomalous wet condition). During the dry years, the anomalous moisture divergence (negative anomalies) at the lower leveldominates in the region (Fig.6b). With low-level divergence and inadequate influx of lowlevel moisture over the study area, convection is suppressed leading to less rainfall and dry condition. However, moisture divergence is depicted in some parts of the country in the north and around lake regions during both wet and dry years. This is attributed to mesoscale effect of orography and convection from the water bodies.

\section{Vertical velocity and velocity potential}

Figure 7 shows composites of vertical velocity anomalies averaged at a fixed longitude (32oE) for wet, dry, and wet-dry years. Figures $(7 a, c)$ reveal that wet years are characterized by ascending motion at low level.This is accompanied by the uplifting airon mountains which favors cloud formationand hence precipitation. However, some descending motion is shownin northern areas above $2 \mathrm{oN}$. This could be attributed to complex topography which might induce downdrafts at low levels (Ogwang et al., 2014). Dry years on the other hand are associated with descending motion at low levels thus subsidence (Fig. 7b). The northern part and areas around the equator are characterized by negative(positive) anomalies at low (mid to high) levels of the studyarea. This implies that only shallow uplift persists over these areas, while the remainingareas experienced subsidence motion and less rainfall.

Figure 8 represents velocity potential anomalies during wet, dry, and wet-dry years. The results reveal that wet years are characterized by positive velocity potential anomalies and convergence at low level over the western Indian ocean and East Africa (Fig.8a). This is accompanied by negative velocity potential and wind divergence at higher levels (Fig.8c), which reposition the ascending limb of the Walker Circulation. This is completed by the descending limb in the eastern part of the Indian Ocean. Dry years are contrarily associated with negative values and a high centre of divergence over East Africa at low level (Fig.8b). This is accompanied by convergence at upper level (Fig.8d) and thus a descending limb of the Walker circulation. These results are in agreement with previous studies conducted including Ogwang et al. (2012), Nicholson et al. (2017), Ayugi et al. (2018) and Limbu \&Tan (2019).

\section{Correlation of rainfall with SST}

Simple correlation analysis was done to establish the relationship between SON rainfall over Uganda and sea surface temperature. The results reveal that SON rainfall and SST over the western Indian Ocean (WIO) tend to positively correlate (Fig. 9a). This is further depicted by temporal correlation between the two variables where a correlation coeffi-

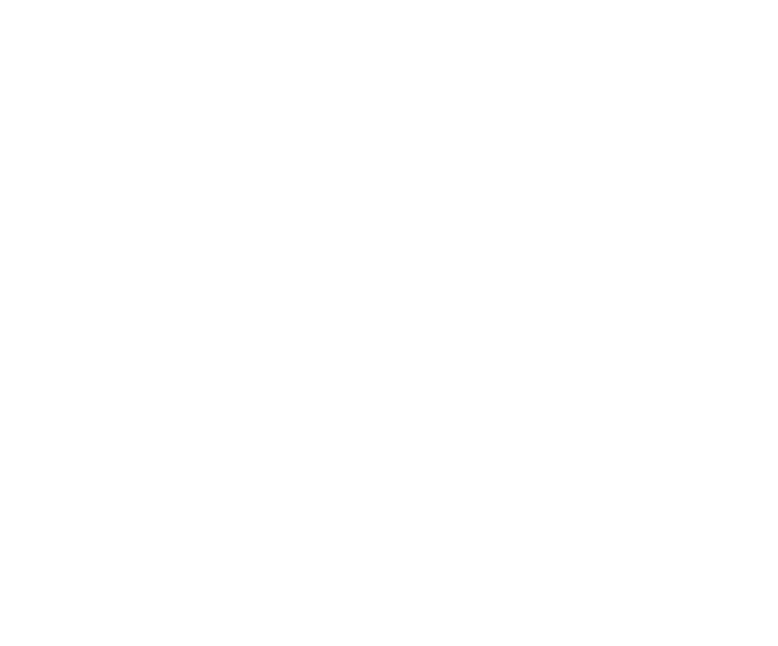

Figure 7. Vertical velocity (omega) anomalies during (a) wet years, (b) dry years and (c) wet-dry years at fixed longitude $\left[32^{\circ} \mathrm{E}\right]$. Negative (positive) values indicate upward (downward) motion. Contour intervalis 0.01 and units are in Pas-1.The shaded area is significantat 0.1 significance level 

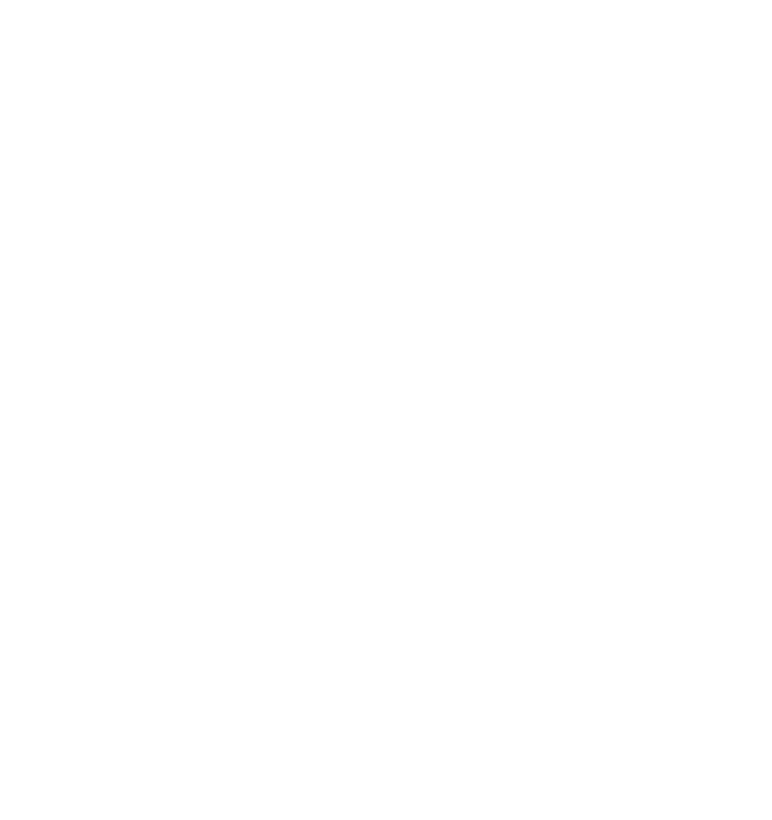

Figure 8. Composite of velocity potential anomalies (contours in $10^{6} \mathrm{~m}^{2} \mathrm{~s}^{-1}$ ) and divergent winds(vectors in $\mathrm{ms}-1$ ) at $850 \mathrm{hPa}(\mathrm{a}, \mathrm{b})$ for wet and dry years, $200 \mathrm{hPa}(\mathrm{b}, \mathrm{c})$ for wet and dry years and 850 $\mathrm{hPa}(\mathrm{e})$ and $200 \mathrm{hPa}(\mathrm{f})$ for wet-dry years over Uganda during 1981-2019. The shaded regions are significant at 0.1 significance level
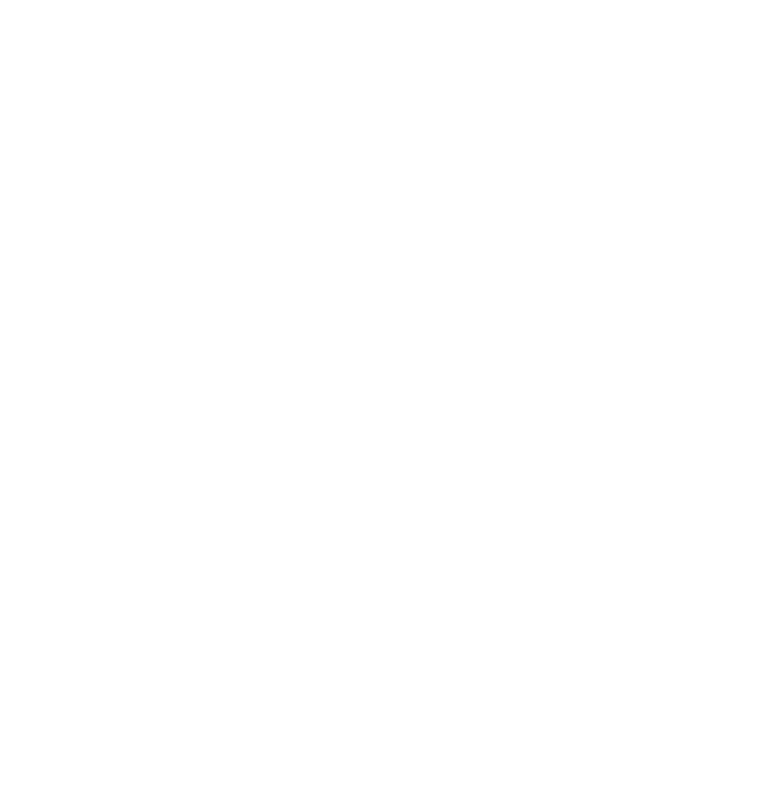

Figure 9. Correlation between standardized SON rainfall anomalies averaged over Uganda and Indian Ocean sea surface temperatures $(a, b)$ and Atlantic Ocean sea surface temperatures (c, d) from 1981-2019. The temporal correlation was obtained by correlating SST over Indian and Atlantic Ocean and SON rainfall averaged over Uganda between longitudes $29^{\circ} \mathrm{E}-36^{\circ} \mathrm{E}$ and latitude $1.5^{\circ} \mathrm{S}-4.5^{\circ} \mathrm{N}$. The dotted regions are significant at 0.05 significance level cient of 0.37 significant at 0.05 significance level is shown (Fig. 9b).The positive anomaly inthe western part of the Indian Ocean enhances convectiveactivity and rising motion from the lower level, whichfacilitates the moisture transport to the study area andhence results in precipitation. However, negative correlation is displayed with SST across the Atlantic Ocean (AO) (Fig. 9c, d). Weak positive correlation is only depicted by small parts of the Atlantic Ocean. These results are in agreement with previous studies including Saji et al. (1999) and Ngarukiyimana et al. (2017) over East Africa. However, a stronger positive correlation with Indian Ocean SST is revealed by the present study compared to the findings of Ngarukiyimana et al. (2017) which correlated SST with MAM rainfall. Cross correlation was performed for rainfall and SST temperature over Indian and Atlantic Ocean (Figure 10a \&b). The results reveal that there
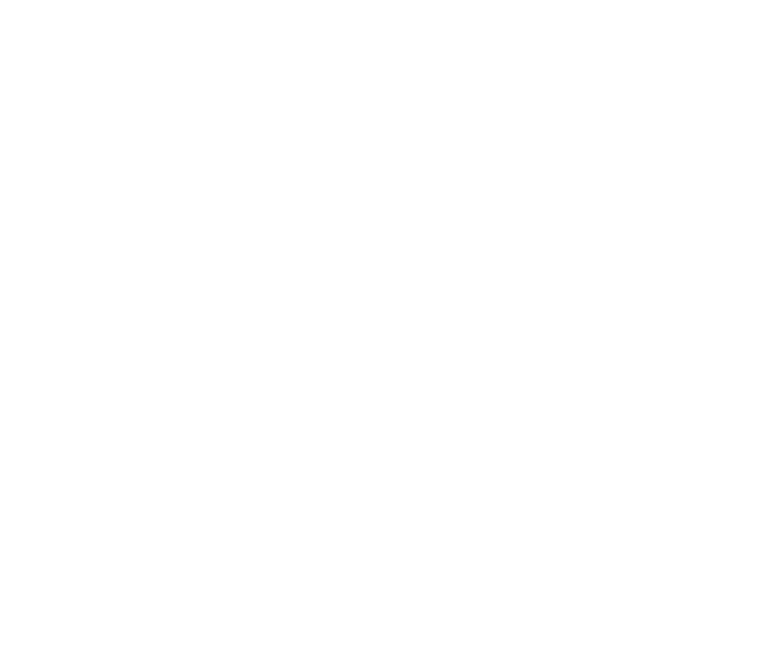

Figure 10. Cross correlation of mean rainfall and sea surface temperature averaged over Uganda for Indian(a) and Atlantic(b) Ocean, and correlation of OND rainfall (one month lead) and SST of Indian (c) and Atlantic (d) ocean during 1981-2019

is a strong correlation between rainfall and SST over WIO and AT when warm SST anomalies lags 6 months i.e during the previous MAM season and when warm SST anomalies leads 3 months. A stronger and more pronounced correlation is shown when the rainfall season is extended i.e October to December instead of SON (Figure $10 \mathrm{c} \& d$ ). In addition, the standard deviation of the wet and dry years in the study period is exhibited 1997 which was a strong El-Nino year captured well. These results thus reveal that anomalous SST over IO and AO during SON impact the SON seasonal rainfall by extending the rains to December and the following months which (December to February) which is normally a dry season over Uganda. 


\section{Correlation of SOI, DMI and SON rainfall}

Southern Oscillation Index (SOI) is based on pressure differences between Tahiti and Darwin. It gives the intensity of El Niño and La Niña events over the Pacific Ocean. Results show that there is negative correlation of SON rainfall and SOI over most parts of Uganda. Positive correlation is depicted by small areas in the west and northern parts of the country (Fig. 10a). Temporal linear correlation coefficient of -0.13 insignificant at 0.05 significance levelis displayed for SON rainfall averaged over Ugandaand SOI. However, stronger positive correlation is revealed with DMI (Fig. 10c). Most areas in the central and southern parts correlate positively with the DMI. The northern and southern parts of the country exhibit varying patterns with negative correlation. These results are in accordance with a previous study by Phillips and McIntyre (2000) which reported that ENSO affects the southern parts of the country differently from the northern areas. Overall, SON rainfall averaged over Uganda exbibits positive correlation with DMI (0.33), significant at 0.05 significance level and negative correlation with SOI $(-0.13)$ insignificant at 0.05 significance level. These findings are in line with previous studies conducted over East Africa (Saji et al., 1999; Ogwang et al., 2014; Ngarukiyimana et al., 2017). Figure 12 (a\&b) represents lead-lag correlation between rainfall and SOI (a), DMI (b) during SON for the period 19812019. Correlation with SOI oscillates throughout the months and strong negative correlation is revealed when SOI leads by 2 and 6 months. A stronger and significant negative correlation $(-0.36)$ at 0.05 significance level is also shown for OND rainfall and SON SOI. A strong correlation is shown when DMI lags 4-3 months than rainfall i.e previous MAM season and leads by 6 months (Figure 12b). Results also reveal correlation of 0.49 between DMI during SON and OND rainfall (Figure 12d). However, this correlation is weaker than that found by Ogwang et al. (2015) of 0.6 over East Africa. The weak correlation of rainfall and SOI could be attributed to the lag of warming in the central and Pacific Ocean compared to the western pacific. Latif and Barnet (1995), indicated that during the warm (cold) events in the tropical Pacific, the tropical Indian Ocean was anomalously warm (cold) while the tropical Atlantic was cold (warm). Black et al. (2003) postulate that ENSO predisposes the Indian Ocean coupled system to an Indian Ocean Zonal Mode (IOZM) event and conclude that only the large events (those that reduce
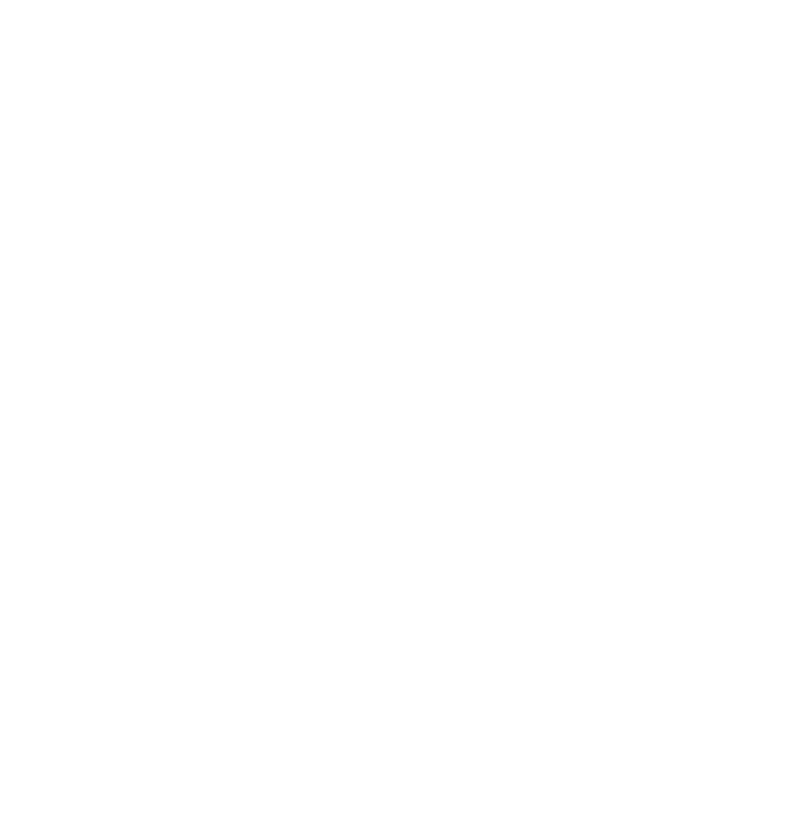

Figure 11. Correlation between SON rainfall anomalies over Uganda and SOI (a, b) and correlation between SON rainfall anomalies averaged over Uganda and DMI (c, d) during 1981-2019. The dotted areas are significant at 0.01 significance level

the Indian Ocean SST gradient) can produce extreme rainfall. These results are in agreement with a previous study (Mafuru \& Guirong, 2020), which found that there is a lag in ENSO events and the upper warm temperature anomalies responsible for inducing rainfall over East Africa.
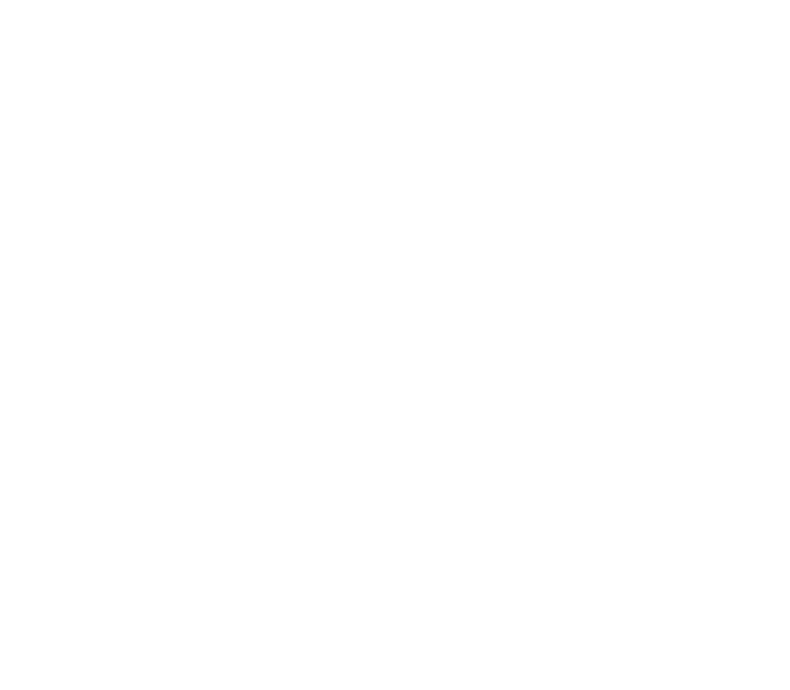

Figure 12. Cross correlation of SST and mean rainfall during SON averaged over Uganda for Indian(a) and Atlantic(b) Ocean, and correlation of OND rainfall (one month lead) and SST of Indian (c) and Atlantic (d) ocean during 1981-2019 


\section{Discussion}

With the high spatiotemporal variability of short rains of September to November over Uganda, this study revisited the mechanisms associated with the anomalous events of rainfall during the SON rainfall. EOF analysis revealed equal number of wet and dry years. Wet (dry) years were depicted during 2001, 2011, 2015 and 2019 (1993, 2005, 2009, 2018).

The results demonstrated that the SON rains are mostly influenced by a Walker circulation over the Indian Ocean. Wet (dry) years are associated with an ascending (descending) limb over the western Indian Ocean. This is characterized by the weakening of the Mascarene High and strengthening of the Arabian High over North Africa. This allows in westerly flow from the Congo basin and this converges with easterlies from the Indian Ocean at low level. This convergence is accompanied by divergence at upper level. Indian Ocean SST exhibited positive correlation whereas Atlantic Ocean SST revealed negative correlation with
SON rainfall over the region. This implies that fluctuations in SST over the Indian Ocean have a great influence on SON rainfall over Uganda. In addition, SON rainfall displayed positive (negative) correlation with DMI (SOI). This agrees with past studies which reported that IOD has more influence on the interannual variability of SON rainfall over Uganda.The results further show that there is a lag in ENSO events and anomalous wet and dry events of rainfall over the region.

The results of this study are in contribution to the understanding of the dynamic and thermodynamics factors responsible for varying patterns of rainfall over Uganda in the recent decades.We recommend an in-depth study about the influence of ENSO on rainfall over Uganda as this study could not bring out deeper analysis. This would help in monitoring of these phenomenon and in generating seasonal forecasts to various sectors like agriculture, fishing, disaster management.

\section{Summary and conclusion}

Rainfall is the key weather parameter over Uganda. Anomalous events affect the country's economy that largely depends on rainfed agriculture. Precipitation over most parts of the country is bimodal with long rains received during MAM and short rains during SON. However, high interannual variability has been witnessed in the short rains which has prompted some farmers to shift the main growing season to this period due to its increased frequency and sometimes duration.

Various mechanisms have been attributed to the varying patterns of the SON rains. This study therefore investigated the circulations and teleconnection mechanisms associated with anomalous events of SON rainfall during the recent decades. The results revealed that a walker circulation over the Indian Ocean influences rainfall during this season. Wet years are characterized by the weakening of the Mascarene High, strong westerlies from the Congo basin at a low level and di- vergence of strong easterlies at the upper level. Indian Ocean SST also have a big influence on SON rainfall over the region compared to Atlantic Ocean SST. In addition, there exists a strong positive correlation of SON rainfall with the DMI. DMI has more effect on rainfall over the region than the SOI. Previous studies have also reported the same finding that ENSO or Pacific Ocean has little contribution to the variability of SON rainfall (Omondi et al., 2013; Liebman et al., 2014; Ngarukiyimana et al., 2017). However, a strong relationship is revealed when there is lag in the ENSO events.ENSO and IOD tend to extend the rainfall season of SON and thus study of extreme events may not be well captured by studies focusing on SON. Future studies might need to consider the season of October to December or December to February. Thus, close monitoring of Indian Ocean SST, wind patterns and the pressure systems; Mascarene High and Arabian Highis crucial in the updating of seasonal forecasts.

\section{Acknowledgments}

Special thanks to Nanjing University of Information Science and Technology for providing a research conducive environment. High gratitude towards the data centers; NOAA, NCEP, ECMWF, the Climate Hazards Center for provision of the datasets employed in the study. The lead author is grateful to Ministry of Commerce of the People's Republic of China for the financial support.Authors would like to thank the editor, and the two anonymous reviewers whose suggestions lead to a substantially improved manuscript. 


\section{Compliance with ethical standards}

All authors declare no conflict of interest for this study.

\section{References}

Ayugi, B. O., Tan, G., Ongoma, V., \& Mafuru, K. B. (2018). Circulations associated with variations in boreal spring rainfall over Kenya. Earth Systems and Environment, 2(2), 421-434. https://doi. org/10.1007/s41748-018-0074-6

Ayugi, B., Tan, G., Ullah, W., Boiyo, R., \& Ongoma, V. (2019). Inter-comparison of remotely sensed precipitation datasets over Kenya during 19982016. Atmospheric Research, 225, 96-109. https:// doi.org/10.1016/j.atmosres.2019.03.032

Basalirwa, C. P. K. (1995). Delineation of Uganda into climatological rainfall zones using the method of principal component analysis. International Journal of climatology, 15(10), 1161-1177.. https:/doi. org/10.1002/joc.3370151008

Bjornsson, S. \& Venegas, H. (1997) A manual for EOF andSVD Analyses of Climatic Data. CGCRReport No. 97-1, McGill University, 8-27.

Black, E., Slingo, J., \& Sperber, K. R. (2003). An observational study of the relationship between excessively strong short rains in coastal East Africa and Indian Ocean SST. Monthly Weather Review, 131(1), 74-94. doi:10.1175/1520493(2003)131<0074:AOSOT $\mathrm{R}>2.0 . \mathrm{CO} ; 2$

Copernicus Climate Change Service (C3S). (2017). ERA5: Fifth generation of ECMWF atmospheric reanalyses of the global climate.Copernicus Climate change Service Climate Data Store (CDS). https://cds.climate.copernicus.edu/cdsapp\#!/home. (Accessed 05.11.2020)

Dinku, T., Funk, C., Peterson, P., Maidment, R., Tadesse, T., Gadain, H., \& Ceccato, P. (2018). Validation of the CHIRPS satellite rainfall estimates over eastern Africa. Quarterly Journal of the Royal Meteorological Society, 144, 292-312. DOI: 10.1002/ qj.3244

Dommenget, D., \& Latif, M. (2002). A cautionary note on the interpretation of EOFs. Journal of climate, 15(2), 216-225.

Egeru, A., Barasa, B., Nampijja, J., Siya, A., Makooma, M. T., \& Majaliwa, M. G. J. (2019). Past, present and future climate trends under varied representative concentration pathways for a sub-humid region in Uganda. Climate, 7(3), 35.

Finney, D. L., Marsham, J. H., Rowell, D. P., Kendon, E. J., Tucker, S. O., Stratton, R. A., \& Jackson, L. S. (2020). Effects of explicit convection on fu- ture projections of mesoscale circulations, rainfall, and rainfall extremes over Eastern Africa. Journal of Climate, 33(7), 2701-2718. DOI: 10.1175/JCLI-D-19-0328.1

Funk, C., Peterson, P., Landsfeld, M., Pedreros, D., Verdin, J., Shukla, S., Husak, G., Rowland, J., Harrison, L., Hoell, A. \& Michaelsen, J. (2015). The climate hazards infrared precipitation with stations-a new environmental record for monitoring extremes. Scientific data, 2(1), 1-21. https://doi. org/10.1038/sdata.2015.66

Government of Uganda, GOU. (2015). Economic Assessment of the Impacts of Climate Change in Uganda. Final Study Report. Ministry of Water and Environment, Climate Change Department, Kampala. url: https://cdkn.org/wp-content/uploads/2015/12/ Uganda CC-economics Final-Report2.pdf

Hastenrath, S., Polzin, D., \& Camberlin, P. (2004). Exploring the predictability of the 'short rains' at the coast of East Africa. International Journal of Climatology: A Journal of the Royal Meteorological Society, 24(11), 1333-1343. doi:10.1002/joc.1070.

Hoell, A., Funk, C., \& Barlow, M. (2014). La Niña diversity and northwest Indian Ocean rim teleconnections. Climate dynamics, 43(9-10), 2707-2724. doi:10.1007/s00382-014-2083-y.

Indeje, M., Semazzi, F. H., \& Ogallo, L. J. (2000). ENSO signals in East African rainfall seasons. International Journal of Climatology: A Journal of the Royal Meteorological Society, 20(1), 19-46. https://doi. org/10.1002/(SICI)1097-0088(200001)20:1<19::AIDOC449>3.0.CO;2-0

Liebmann, B., Hoerling, M. P., Funk, C., Bladé, I., Dole, R. M., Allured, D., Quan X., Pegion, P. \& Eischeid, J. K. (2014). Understanding recent eastern Horn of Africa rainfall variability and change. Journal of Climate, 27(23), 8630-8645. doi:10.1175/JCLID-13-00714.1.

Limbu, P. T. S., \& Guirong, T. (2019). Relationship between the October-December Rainfall in Tanzania and the Walker Circulation Cell over Indian Ocean. Meteorologische Zeitschrift, 28(6), 453-469. DOI 10.1127/metz/2019/0939.

Lorenz, E. N. (1956). Empirical orthogonal functions and statistical weather prediction. Technical report, StatisticalForecast Project Report 1. Department of Meteorology. MIT, 49pp. 
Mafuru, K. B., \& Guirong, T. (2020). The influence of ENSO on the upper warm temperature anomaly formation associated with the March-May heavy rainfall events in Tanzania. International Journal of Climatology, 40(5), 2745-2763. https://doi. org/10.1002/joc.6364

Makkonen, L. (2006). Plotting positions in extreme value analysis. Journal of Applied Meteorology and Climatology, 45(2), 334-340.

Manatsa, D., Chipindu, B., \& Behera, S. K. (2012). Shifts in IOD and their impacts on association with East Africa rainfall. Theoretical and Applied Climatology, 110(1), 115-128. doi:10.1007/s00704-0120610-5.

Manatsa, D., Morioka, Y., Behera, S. K., Matarira, C. H., \& Yamagata, T. (2014). Impact of Mascarene High variability on the East African 'short rains'. Climate dynamics, 42(5-6), 1259-1274. doi:10.1007/s00382-013-1848-z.

Manatsa, D., Mudavanhu, C., Mushore, T. D., \& Mavhura, E. (2016). Linking major shifts in East Africa 'short rains' to the Southern Annular Mode. International Journal of Climatology, 36(4), 1590-1599. doi:10.1002/joc.4281

Mutai, C., Polzin, D., \& Hastenrath, S. (2012). Diagnosing Kenya rainfall in boreal autumn: Further exploration. Journal of climate, 25(12), 4323-4329. doi:10.1175/JCLI-D-11-00414.1.

Ngarukiyimana, J. P., Fu, Y., Yang, Y., Ogwang, B. A., Ongoma, V., \& Ntwali, D. (2018). Dominant atmospheric circulation patterns associated with abnormal rainfall events over Rwanda, East Africa. International Journal of Climatology, 38(1), 187-202. doi: 10.1002/joc.5169

Ngoma, H., Wen, W., Ojara, M., \& Ayugi, B. (2021). Assessing current and future spatiotemporal precipitation variability and trends over Uganda, East Africa, based on CHIRPS and regional climate model datasets. Meteorology and Atmospheric Physics, 1-21. https://doi.org/10.1007/s00703-021-00784-3

Nicholson, S. E., \& Kim, J. (1997). The relationship of the El Niño-Southern oscillation to African rainfall. International Journal of Climatology: A Journal of the Royal Meteorological Society, 17(2), 117135. doi:10.1002/(SICI)1097-0088(199702)17:2<117: AID-JOC84>3.0.CO;2-O

Nicholson, S. E. (1996). A review of climate dynamics and climate variability in eastern Africa. In Johnson T.C. \& Odada E.O. (Eds.) The Limnology, Climatology, and Paleoclimatology of the East African Lakes, (pp. 25-56), Amsterdam: Gordon and Breach Publ.

Nicholson, S. E.,Leposo, D\&Grist, J.P., (2001). The relationship between El Niño and drought over Botswana, Journal of Climate., 14(3),
323-335,doi:10.1175/1520-0442(2001)014<0323:TR $\mathrm{BENO}>2.0 . \mathrm{CO} ; 2$.

Nicholson, S. E. (2015). Long-term variability of the East African 'short rains' and its links to large-scale factors. International Journal of Climatology, 35(13), 3979-3990. doi:10.1002/joc.4259.

Nicholson, S. E. (2017). Climate and climatic variability of rainfall over eastern Africa. Reviews of Geophysics, 55(3), 590-635. doi:10.1002/2016RG000544

Nicholson, S. E. (2018). The ITCZ and the seasonal cycle over equatorial Africa. Bulletin of the American Meteorological Society, 99(2), 337-348. https://doi. org/10.1175/BAMS-D-16-0287.1

Nsubuga, F. W., \& Rautenbach, H. (2018). Climate change and variability: a review of what is known and ought to be known for Uganda. International Journal of Climate Change Strategies and Management. Doi 10.1108/IJCCSM-04-2017-0090

Nsubuga, F.N.W., Olwoch, J. M., Rautenbach, C. D., \& Botai, O. J. (2014). Analysis of mid-twentieth century rainfall trends and variability over southwestern Uganda. Theoretical and applied climatology, 115(1), 53-71. https://doi.org/10.1007/s00704-013-0864-6

Ogwang, B., Nimusiima, A., Tindamanyire, T., Serwanga, M., Ayesiga, G., Ojara, M., Ssebabi, F., Gugwa, G., Nsubuga, Y., Atim, R., \& Aribo, L. (2016). Characteristics and changes in SON rainfall over Uganda (1901-2013). Journal of Environmental and Agricultural Sciences, 8, 45-53.

Ogwang, B. A., Ongoma, V., Xing, L., \& Ogou, K. F. (2015). Influence of Mascarene high and Indian Ocean dipole on East African extreme weather events. Geographica Pannonica, 19(2), 64-72. https://doi.org/10.5937/geopan15020640

Ogwang, B. A., Chen, H., Li, X., \& Gao, C. (2014). The influence of topography on East African October to December climate: sensitivity experiments with RegCM4. Advances in Meteorology. https:/doi. org/10.1155/2014/143917

Ogwang, B. A., Guirong, T., \& Haishan, C. (2012). Diagnosis of September-November drought and the associated circulation anomalies over Uganda. Pakistan Journal of Meteorology, 9(2).11-24

Ojara, M. A., Lou, Y., Aribo, L., Namumbya, S., \& Uddin, M. J. (2020). Dry spells and probability of rainfall occurrence for Lake Kyoga Basin in Uganda, East Africa. Natural Hazards, 100(2), 493-514.. https://doi.org/10.1007/s11069-019-03822-x

Ongoma, V., Tan, G., Ogwang, B., \& Ngarukiyimana, J. (2015). Diagnosis of seasonal rainfall variability over East Africa: a case study of 2010-2011 drought over Kenya. Pakistan Journal of Meteorology, 11(22), 13-21.

Phillips, J., \& McIntyre, B. (2000). ENSO and interannual rainfall variability in Uganda: implications for 
agricultural management. International Journal of Climatology: A Journal of the Royal Meteorological Society, 20(2), 171-182.

Reliefweb., (2020). UgandaKey Message Update:Areas affected by flooding and landslides face deteriorating food security as food prices rise, January 2020. Available at: https://reliefweb.int/report/uganda/ uganda-key-message-update-areas-affected-flooding-and-landslides-face-deteriorating. (Accessed 18.12.2020).

Saji, N. H., Goswami, B. N., Vinayachandran, P. N., \& Yamagata, T. (1999). A dipole mode in the tropical Indian Ocean. Nature, 401(6751), 360-363. https:// doi.org/10.1038/43854

Sylla, M. B., Giorgi, F., Coppola, E., \& Mariotti, L. (2013). Uncertainties in daily rainfall over Africa: assessment of gridded observation products and evaluation of a regional climate model simulation. International Journal of Climatology, 33(7), 1805-1817. https://doi.org/10.1002/joc.3551

Uganda National Meteorological Authority (UNMA). (2019). September to December 2019 seasonal rainfall outlook over Uganda. Available at: http://www. unma.go.ug

Wainwright, C. M., Finney, D. L., Kilavi, M., Black, E., \& Marsham, J. H. (2021). Extreme rainfall in East Africa, October 2019-January 2020 and context under future climate change. Weather, 76(1), 26-31. doi: 10.1002/wea.3824

Williams, A. P., \& Funk, C. (2011). A westward extension of the warm pool leads to a westward extension of the Walker circulation, drying eastern Africa. Climate Dynamics, 37(11-12), 2417-2435. https:// doi.org/10.1007/s00382-010-0984-y 